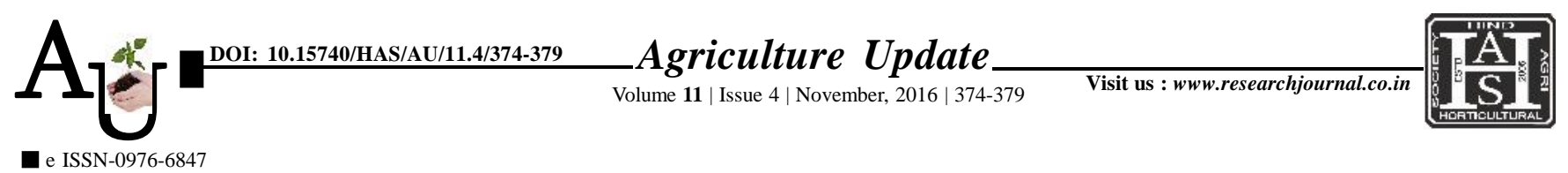

\title{
Research Article: Impact of uzhavar sandhai on livelihood empowerment of farmers
}

\section{K. INDUMATHY, R. RAJASEKARAN AND N. SUGANTHI}

Article Chronicle:

Received :

20.08.2016;

Revised :

21.09.2016;

Accepted :

07.10 .2016

KEY WoRDS:

Uzhavar, Sandhai,

Livelihood,

Empowerment,

Impact analysis,

Decision alternatives,

Marketing

Author for correspondence :

\section{K. INDUMATHY}

Department of

Agricultural Extension,

Adhiparasakthi

Agricultural College,

G.B.Nagar, Kalavai,

VELLORE (T.N.) INDIA

Email: induagri18@

gmail.com

See end of the article for

authors' affiliations
SUMMARY : The study was conducted to assess the impact and decision alternatives of farmers towards uzhavar sandhai. Totally 7 uzhavarsandhais present in Vellore district, out of that 4 uzhavarsandhais were selected based on convenience sampling technique. The uzhavar sandhais were selected from four blocks of Vellore, Arcot, Ranipet and Katpadi. Totally 90 respondents were composed through random sampling method. A survey was conducted and interview schedule was used to collect the data. Based on the collected data, the variables were analysed by using SPSS software and the results are predicted. The results show that the majority of the farmers belong to middle age category. Majority (52.20\%) of the respondents were marginal farmers who were holding the land size upto 2.5 acres. Half of the farmers were attending the market from the year 2000 onwards. Three fourth 75.00 per cent of the respondent's primary occupation was farming. Three fifth $(73.00 \%)$ of the respondents were having moderate accessibility with the uzhavar sandhai. Two fifth (68.9\%) of the respondents were medium level decision alternatives followed by low level $(18.90 \%)$.

How to cite this article : Indumathy, K., Rajasekaran, R. and Suganthi, N. (2016). Impact of uzhavar sandhai on livelihood empowerment of farmers. Agric. Update, 11(4): 374-379; DOI : 10.15740/HAS/AU/11.4/374-379. 